\title{
Comparative assessment of population genetics and demographic history of two congeneric deep sea fish species living at different depths
}

\author{
Thomas A. White, Heather A. Fotherby, A. Rus Hoelzel* \\ School of Biological and Biomedical Sciences, University of Durham, Durham DH1 3LE, UK
}

\begin{abstract}
The mechanisms that determine population genetic structure in the marine environment are poorly understood, as are the processes that drive population dynamics. One potential factor is depth, with especially those species living in the abyss inhabiting a distinct environment with respect to habitat complexity, pressure, the distribution of resources and environmental change over time. Here we consider a deep sea fish genus, Coryphaenoides, which has many named species, including 8 abyssal species. We provide data in support of the existence of 2 distinct evolutionary lineages within the genus, associated with depth, and also provide detailed population genetic data for the abyssal species (C. brevibarbis) for comparison with available data on a congeneric species inhabiting shallower waters (C. rupestris). The abyssal species showed no sign of population genetic structure across a thermal oceanographic boundary (the Sub-Polar Front), for which C. rupestris showed differentiation. An assessment of historical demographics suggested a decline in population size for both species, but a faster and more severe decline for the abyssal species. We consider these data in the context of environmental gradients and potential evolutionary mechanisms. Relatively low effective population size estimates for both species emphasize the importance of understanding these processes for the effective conservation and management of deep sea fish stocks.
\end{abstract}

KEY WORDS: Population genetics $\cdot$ Demographic decline $\cdot$ Marine fish $\cdot$ Deep sea

\section{INTRODUCTION}

The relationship between habitat, population dynamics and population structure has been investigated in various systems, and may be expected to show a dependency on aspects of habitat stability, carrying capacity and physical requirements. For example, Marten et al. (2006) found that habitat type predicts population differentiation for invertebrate species (including 150 species in a meta-analysis) in lentic (standing) versus lotic (running) freshwater habitats, though the effect was small (as expected due to the large number of possible contributing factors). The authors suggest that differences in the temporal and spatial stability of the 2 habitats explain the differentiation, with species needing to adopt strategies involving strong gene flow in the less permanent lentic habitats. There are some parallels with the deep sea, with the abyss being more uniform and perhaps less productive than shallower waters, and therefore potentially promoting greater gene flow (see Etter et al. 2005, and the 'Discussion' section). However, not all studies have found a strong relationship between habitat and population structure. Blank et al. (2007) found no effect for deciduous versus mixedconiferous habitat on population structure comparing great tits Parus major and blue tits P. caeruleus. Further, Shikano et al. (2010) studying the European nine-spine stickleback Pungitius pungitius considered the relative importance of habitat type (coastal versus freshwater) compared to demographic history (in the context of postglacial colonization) and found that, although habitat type had an effect, a stronger effect was related to founder events during postglacial colonization. In the present study we consider the possible influence of 
habitat in the deep sea, and focus on 2 species inhabiting different depths with respect to their population size, structure and dynamics over time.

Deep water at the Mid-Atlantic Ridge of the North Atantic is inhabited by at least 16 macrourid species in 9 genera (Bergstad et al. 2008a). The most numerically dominant genus is Coryphaenoides. In particular, the species C. rupestris, C. brevibarbis and C. armatus rank amongst the most abundant demersal fishes on the ridge or in the deep axial valleys and fracture zones.

The round-nosed grenadier Coryphaenoides rupestris is a deep-sea demersal fish distributed across the North Atlantic and found primarily at a depth range of 800 to 2600 m (Coad \& Reist 2004). A commercial fishery for C. rupestris began in the NW Atlantic in 1967 (Atkinson 1995), with declining catches since the 1970s (Koslow et al. 2000), resulting in an estimated 99.6\% decline in abundance over a period of $26 \mathrm{yr}$ (Devine et al. 2006). In the NE Atlantic, fisheries began in the 1970 s, quickly peaking before undergoing a severe decline (Koslow et al. 2000) with an estimated loss in spawning biomass to approximately $30 \%$ of pre-fishery levels (ICES 2002).

Previous work on this species has identified geographically well-separated spawning areas in Norwegian fjords and in the Skagerrak (Bergstad 1990, Bergstad \& Gordon 1994), as well as evidence for genetic structuring associated with the Sub-Polar Front (White et al. 2010a). Selection at an unknown gene linked to a neutral locus was also proposed in the context of sampling depth, predominantly in the eastern portion of its distribution in the North Atlantic (White et al. 2010a).

The shortbeard grenadier Coryphaenoides brevibarbis is a deep-sea fish distributed in the North Atlantic, at depths of 1500 to $4700 \mathrm{~m}$ (Bergstad et al. 2008b), where it feeds on copepods, amphipods and mysids (Gordon \& Duncan 1987). While this species is not commercially important itself, it is a common bycatch in deep-water fisheries. Comparatively little is known about this species.

A defining characteristic of the genus Coryphaenoides is the use of demersal habitat at depth; however, only a proportion of the species in the genus are found in very deep (abyssal) water. Among the 65 named species in the genus, 8 are found at depths $>4000 \mathrm{~m}, 16$ at depths $>3000 \mathrm{~m}$ and 33 at depths of $2000 \mathrm{~m}$ or greater. The other 32 species have been recorded at maximum depths of from 457 to $1870 \mathrm{~m}$, though there are very few data available for some of the species in this genus (see www.fishbase.org).

Our objective in the present study is to compare 2 well-sampled species within the genus, 1 found deeper and 1 found shallower than $4000 \mathrm{~m}$, and consider their population genetics and historical demographics in that context. Among the 8 species found at depths $>4000 \mathrm{~m}, 6$ have been sequenced for the COI mtDNA gene. We combined all 9 species for which COI sequences were available with our own data for $C O I$ for Coryphaenoides rupestris and C. brevibarbis to consider the phylogenetic relationship between our focal species. We tested the hypothesis that the abyssal species, with different environmental influences, will show a distinct population structure in the focal area, and different historical demographics. Each of the focal study species have been subject to recent periods of intensive fishing and likely shifts in habitat characteristics over Quaternary climatic cycles; however, differences associated with life history or depth may have impacted their consequent demographic and population genetic profiles.

\section{MATERIALS AND METHODS}

Coryphaenoides brevibarbis sampling and genetic analysis. C. brevibarbis samples were collected on either side of the sub-polar front, spanning a distance of $780 \mathrm{~km}$ between the most distant points (NW2 and SE2), and $270 \mathrm{~km}$ at the shortest point across the front (NE2 and SE1). Samples were collected by an OTSB trawl towed on a single warp (Gordon \& Bergstad 1992) from the RRS 'James Cook'. The present study shares sampling sites with our earlier study of the congeneric species $C$. rupestris, where differentiation was found across this putative boundary (White et al. 2010a) over a range of $270 \mathrm{~km}$. In total, 380 individuals of C. brevibarbis were obtained from 7 sampling sites on the MidAtlantic ridge (MAR; Table 1, Fig. 1). Population genetic analysis for C. rupestris is reported elsewhere (White et al. 2010a). Here we report sampling and genetic analysis for C. brevibarbis, but the sampling was conducted during the same project as that described by White et al. (2010a), and samples were collected from 2 of the same sampling sites (NE1 \& SE1) and 1 site proximate to one of the C. rupestris sites (SE2 near Faraday; see Fig. 1), providing the opportunity for a direct comparison.

DNA was extracted from specimens using a phenolchloroform protocol (after Hoelzel 1998). A total of 17 microsatellite DNA loci were PCR amplified; 13 of these were previously described by White et al. (2010b): Cbre2, Cbre6, Cbre12, Cbre13, Cbre14, Cbre19, Cbre20, Cbre26, Cbre27, Cbre30, Cbre32, Cbre40 and Cbre43. Two were described by White et al. (2008): CorRu1 and CorRu28. Crup 7 was described by Knutsen et al. (2008), and CaraC7 was described by Schneider et al. (2009). Polymerase chain reactions (PCR) were carried out using Qiagen multiplex PCR kits in a total volume of $10 \mu \mathrm{l}$ reaction ${ }^{-1}$. This volume comprised $5 \mu \mathrm{l}$ of 
Table 1. Sampling information and summary statistics for each sampling site. Values in bold indicate significant departure from Hardy-Weinberg equilibrium, assessed in Arlequin using exact tests. n: sample size; $H_{\mathrm{e}}$ and $H_{\mathrm{o}}$ : mean expected and observed heterozygosity, respectively; $A$ : mean alleles per locus; $A_{\text {rich }}$ : mean allelic richness; $F_{\mathrm{IS}}$ : mean inbreeding coefficient (p-values in parentheses); SPF: Sub-Polar Front; MAR: Mid-Atlantic Ridge

\begin{tabular}{|lcccccccccccc|}
\hline $\begin{array}{l}\text { Sampling } \\
\text { site }\end{array}$ & Latitude & Longitude & $\begin{array}{c}\text { Side } \\
\text { of } \\
\text { SPF }\end{array}$ & $\begin{array}{c}\text { Side } \\
\text { of } \\
\text { MAR }\end{array}$ & $\begin{array}{c}\text { Beographic } \\
\text { gluster }\end{array}$ & $\begin{array}{c}\text { Depth } \\
(\mathrm{m})\end{array}$ & $\mathrm{n}$ & $H_{\mathrm{e}}$ & $H_{\mathrm{o}}$ & $A$ & $A_{\text {rich }}$ & $F_{\text {IS }}$ \\
\hline SE1 & $51.55^{\circ} \mathrm{N}$ & $30.25^{\circ} \mathrm{W}$ & $\mathrm{S}$ & $\mathrm{E}$ & 1 & 1910 & 24 & 0.79 & 0.79 & 11.80 & 11.04 & $0.00(0.120)$ \\
$\mathrm{NE} 1$ & $52.59^{\circ} \mathrm{N}$ & $34.52^{\circ} \mathrm{W}$ & $\mathrm{N}$ & $\mathrm{E}$ & 2 & 1650 & 23 & 0.74 & 0.69 & 10.73 & 9.97 & $\mathbf{0 . 0 7}(\mathbf{0 . 0 0 6})$ \\
$\mathrm{NE2}$ & $53.02^{\circ} \mathrm{N}$ & $33.37^{\circ} \mathrm{W}$ & $\mathrm{N}$ & $\mathrm{E}$ & 2 & 3030 & 48 & 0.75 & 0.74 & 14.27 & 10.40 & $\mathbf{0 . 0 2 ( 0 . 0 0 0 )}$ \\
$\mathrm{NE3}$ & $53.08^{\circ} \mathrm{N}$ & $34.46^{\circ} \mathrm{W}$ & $\mathrm{N}$ & $\mathrm{E}$ & 2 & 2350 & 111 & 0.76 & 0.73 & 19.13 & 10.57 & $\mathbf{0 . 0 4}(\mathbf{0 . 0 0 0 )}$ \\
$\mathrm{NW} 1$ & $53.17^{\circ} \mathrm{N}$ & $35.32^{\circ} \mathrm{W}$ & $\mathrm{N}$ & $\mathrm{W}$ & 3 & 2548 & 55 & 0.76 & 0.76 & 15.93 & 10.77 & $0.00(0.099)$ \\
$\mathrm{NW} 2$ & $53.57^{\circ} \mathrm{N}$ & $36.13^{\circ} \mathrm{W}$ & $\mathrm{N}$ & $\mathrm{W}$ & 3 & 2627 & 87 & 0.76 & 0.76 & 17.33 & 10.53 & $0.00(0.021)$ \\
$\mathrm{SE2}$ & $49.06^{\circ} \mathrm{N}$ & $27.50^{\circ} \mathrm{W}$ & $\mathrm{S}$ & $\mathrm{E}$ & 4 & 2739 & 32 & 0.76 & 0.74 & 13.20 & 10.97 & $0.02(0.029)$ \\
\hline
\end{tabular}

multiplex PCR master mix, $4 \mu \mathrm{l}$ of primer master mix (with each primer at a concentration of $0.5 \mu \mathrm{M}$ ) and $1 \mu \mathrm{l}$ of template DNA. PCR was performed with the profile: hot-start activation at $95^{\circ} \mathrm{C}$ for $15 \mathrm{~min}, 35$ cycles of $30 \mathrm{~s}$ denaturing at $94{ }^{\circ} \mathrm{C}, 90 \mathrm{~s}$ annealing at $57^{\circ} \mathrm{C}, 60$ s extension at $72^{\circ} \mathrm{C}$ and final extension at $60^{\circ} \mathrm{C}$ for 10 mins. Loci were multiplexed in 2 sets of 8 and 9 loci, respectively. Forward primers were 5' fluorescently labelled using either FAM, HEX (Eurofin), or NED (Applied Biosystems) for screening of alleles on the ABI 3730 sequencer. Alleles were scored using PEAK SCANNER

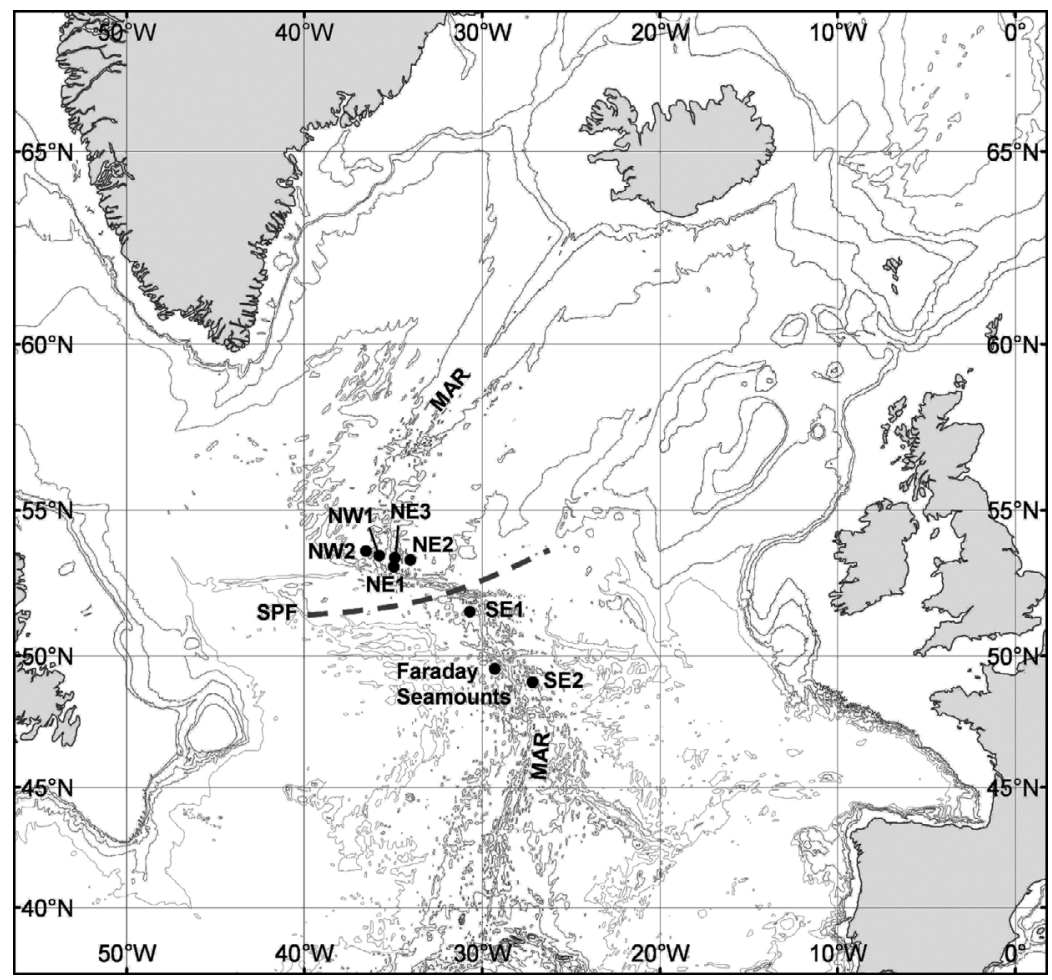

Fig. 1. Sampling sites in the North Atlantic. SPF: Sub-Polar Front; MAR: MidAtlantic Ridge
V1.0 (Applied Biosystems), with GS 500 as the internal size standard. Alleles were binned using the program FLEXIBIN V2 (Amos et al. 2006).

For each sampling site, expected heterozygosities, allelic richness and $F_{\text {IS }}$ (Wright's inbreeding coefficient) were calculated using GENEPOP (Raymond \& Rousset 2005). Significance of deviation from HardyWeinberg Equilibrium (HWE) was evaluated using exact tests. The program MICROCHECKER V2.2.3 (Van Oosterhout et al. 2004) was used to test for allele scoring errors and the existence of null alleles. MICROCHECKER found evidence of null alleles in $>1$ sample for the loci Cbre 6 and Cbre20. Therefore, further analyses were conducted without these loci.

Including loci under selection can sometimes distort population genetic analyses (White et al. 2010a). Therefore, we used a Bayesian approach to detect loci potentially under selection, implemented in the program BAYESCAN (Foll \& Gaggiotti 2008). $F_{\text {ST }}$ (Wright's interpopulation inbreeding coefficient) values reflect contributions from locus-specific effects, such as selection, and population-specific effects, such as genetic drift and immigration rates (Balding \& Nichols 1995). BAYESCAN uses a hierarchical Bayesian approach to estimate the locus and population effects on these $F_{\text {ST }}$ values. Following the suggestion of Foll \& Gaggiotti (2008), we used the 'decisive' criterion under Jeffrey's scale of evidence to identify outlier loci, in order to minimize the false-positive rate and to maximize the true-positive rate. No loci emerged as outliers under selection. 
Overall and pairwise $F_{\mathrm{ST}}$ (Weir \& Cockerham 1984) among sampling sites in the North Atlantic were calculated using ARLEQUIN 3.5 (Excoffier \& Lischer 2010), and the significance of the difference between the observed $F_{\mathrm{ST}}$ and zero was evaluated using exact tests.

We used the program POWSIM 4.1 (Ryman \& Palm 2006) to assess the statistical power of our analysis to reject the null hypothesis of genetic homogeneity for different combinations of number of samples, sample sizes, number of loci, number of alleles and allele frequencies for a hypothetical degree of true differentiation (quantified as $F_{\mathrm{ST}}$ ).

We also conducted AMOVA in ARLEQUIN 3.5, with several different hierarchical structures relating to barriers that are thought or known to influence gene flow (White et al. 2010a). Firstly, sampling sites were grouped according to the side of the Sub-Polar Front (SPF) on which they fell (north vs. south). Secondly, they were grouped according to the side of the MAR (west vs. east). Finally, sampling sites were placed in 1 of 4 groups, based on the side of the SPF and the side of the MAR.

Phylogeny of the genus Coryphaenoides. Database sequences for Coryphaenoides species for the COI locus were compared with sequences derived for 3 samples each of C. rupestris and C. brevibarbis. From the database there were 2 sequences for $C$. leptolepis (EU148126-7; direct submission), 2 for $C$. guentheri (EU148124-5; direct submission), 3 for C. carapinus (EU148120-2; direct submission), 2 for $C$. brevibarbis (EU148118-9; direct submission), 4 for $C$. armatus (EU148115-7; FJ164497; direct submission; Steinke et al. 2009), 2 for C. yaquinae (GU440291-2; direct submission), 5 for C. cinereus (FJ164498-502; Steinke et al. 2009), 9 for C. acrolepis (FJ164488-96; Steinke et al. 2009) and 3 for C. mediterraneus (EU148128-30; direct submission). Previous phylogenies have been presented comparing some of these species (e.g. Morita 1999, Roa-Varon \& Orti 2009); here we extend the comparison between abyssal and shallow-water species. Three outgroup species were included: Macrourus holotrachys (EU074455), Coelorinchus marinii (EU074385) and Pseudonezumia flagellicauda (EU148298). PCR primers coryco1F (ATA CCT C/T GT G/A TTT GGT GC) and coryco1R (GGT AAG G/A TTT CG G/A TCT GT) were designed from the alignment of the available sequences within the genus. PCR amplification used the Qiagen multiplex kit: $10 \mu \mathrm{l}$ of the master mix, $2 \mu \mathrm{M}$ of each primer and $\sim 100 \mathrm{ng}$ template DNA in a $20 \mu \mathrm{l} \mathrm{vol-}$ ume. The cycle conditions were $95^{\circ} \mathrm{C}$ for $15 \mathrm{~min}, 94^{\circ} \mathrm{C}$ for $30 \mathrm{~s}, 50^{\circ} \mathrm{C}$ for $1 \mathrm{~min} 30 \mathrm{~s}$ and $72^{\circ} \mathrm{C}$ for $1 \mathrm{~min}$, for 35 cycles, with a final elongation step at $60^{\circ} \mathrm{C}$ for $10 \mathrm{~min}$. Sequencing was by the chain termination method on an ABI 3730, in both directions. The sequence length produced was $566 \mathrm{bp}$, and all sequences were compared at that length. The best evolution model for the trees was assessed using Modeltest 3.7 (Posada \& Crandall 1998). Phylogenies were run in PAUP using the maximum parsimony (data not shown) and neighbour-joining (NJ) methods with 1000 bootstrap replicates and the Jukes-Cantor evolution model for the NJ tree (which had the highest support from Modeltest). Trees were also constructed in MR BAYES 3.1.2 (Huelsenbeck \& Ronquist 2001, Ronquist \& Huelsenbeck 2003) based on the same model to provide Bremmer support values. All estimates for the depth ranges of individual species were taken from their entries in FishBase (www.fishbase.org/).

Demographic history of Coryphaenoides rupestris and $\boldsymbol{C}$. brevibarbis. The software DIYABC (Cornuet et al. 2008) was used to estimate the effective population sizes for C. rupestris and C. brevibarbis. For all runs of DIYABC, we defined 2 models, 1 assuming constant population size and 1 allowing a population size change at $t$ generations in the past. For $C$. rupestris, we ran 2 trials for separate local samples. This was to guard against a Wahlund effect, even though the 2 populations chosen had shown no significant differentiation based on 11 microsatellite DNA loci (White et al. 2010a), and to provide replicate tests. The first run was based on 91 samples from SE1 (see Fig. 1) and 2000000 simulated data sets. The second run was based on 97 individuals from the Faraday Seamounts site and 3000000 simulated data sets (Fig. 1). Two runs are also presented for $C$. brevibarbis; the first includes all 380 samples and is based on 2000000 simulated data sets. The second was based on just 1 local sample of 111 individuals from the NE3 site (Fig. 1; the largest local sample for this species) and 2000000 simulated data sets. This was again to test for consistency. There was no differentiation between sites, and so no need to do all sites separately. Prior distributions were set for $N_{\mathrm{e}}$ (uniform distribution lower limit 100, upper limit 100000 ), $t$ (uniform distribution lower limit 1 , upper limit 100000 ), mean $\mu$ (uniform distribution lower limit $1 \times 10^{-5}$, upper limit $1 \times 10^{-2}$ ) and locus $\mu$ (gamma distribution lower limit $1 \times 10^{-5}$, upper limit $1 \times 10^{-2}$, shape 2.0), mean $P$ (uniform distribution lower limit 0.1, upper limit 0.3) and locus $P$ (gamma distribution lower limit 0.01, upper limit 0.9, shape 2.0).

\section{RESULTS}

\section{Phylogeny of the genus Coryphaenoides}

All trees showed the same lineage structure, and the NJ tree is shown together with support for the same nodes from the analysis in MR BAYES (Fig. 2). Two main lineages are well supported by all analyses, and these grouped according to the maximum depth at 


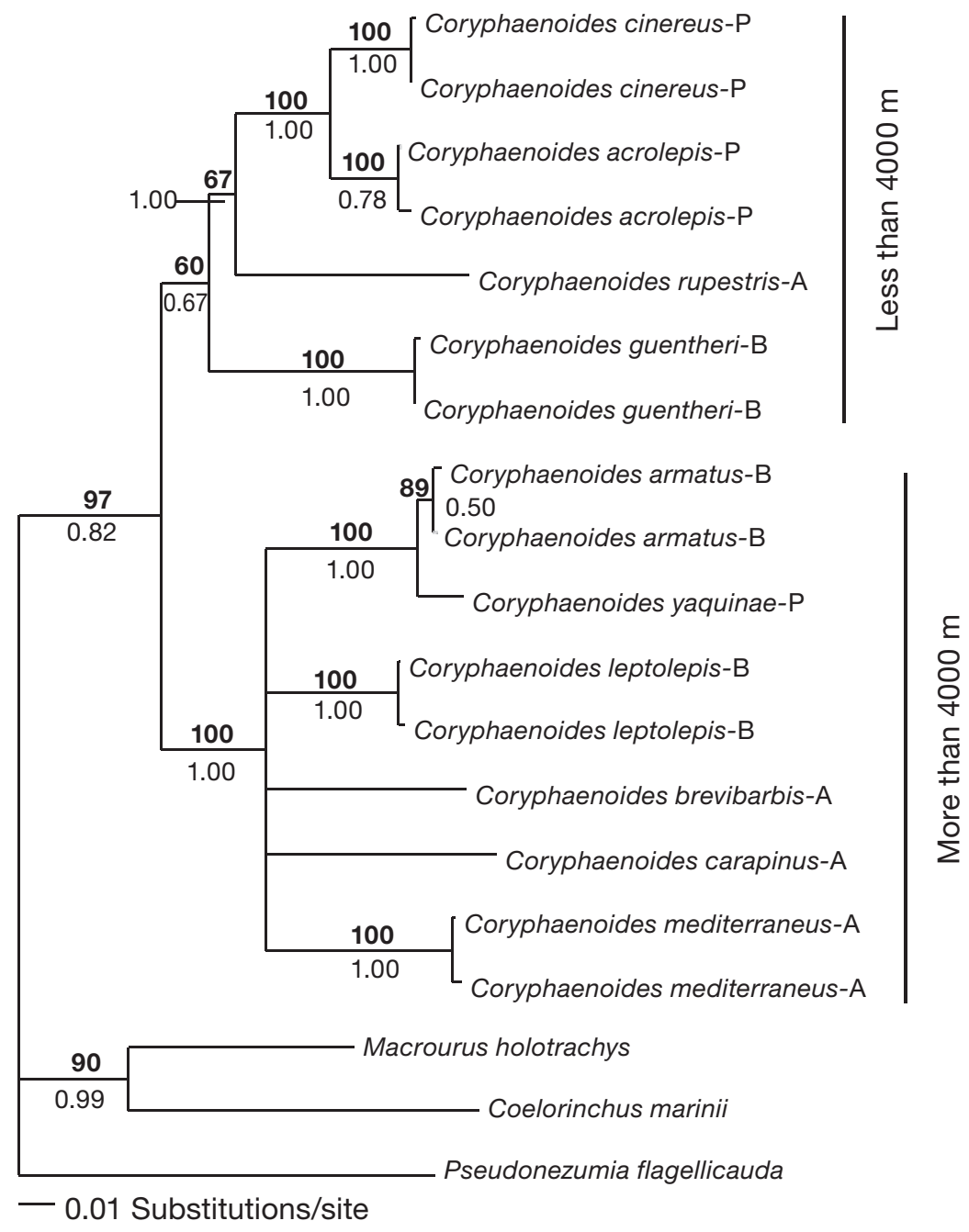

Fig. 2. Neighbour-joining tree of COI sequences with percent bootstrap support (in bold text above branches) and Bremmer support values from a Bayesian tree (below branches) shown; the maximum depth range is also indicated. After each Coryphaenoides taxon there is a code to indicate origin - A: Atlantic; P: Pacific ${ }_{i}$ B: both Atlantic and Pacific

which the species within each lineage have been found (less than or more than $4000 \mathrm{~m}$ ). Out of 45 available sequences representing 10 Coryphaenoides species there were 16 unique sequences. There was no apparent pattern with respect to species distribution, with species from each lineage being found in the Atlantic and in the Pacific. One of our focal study species is represented in each lineage.

\section{Coryphaenoides brevibarbis genetic analysis}

$F_{\text {ST }}$ over all samples was 0.0002 and not significant. POWSIM suggested that with our loci and our sampling regime, we would have $99.5 \%$ power to detect significant genetic differentiation when $F_{\mathrm{ST}}=0.002,77.5 \%$ power to detect significant genetic differentiation when $F_{\mathrm{ST}}=0.001$ and $36 \%$ power when $F_{\mathrm{ST}}=0.0005$. $F_{\mathrm{IS}}$ was marginally positive and significant at several sample locations (Table 1). Significant results are from the NE region, but marginally significant results are seen at other sites and variation in $F_{\text {IS }}$ values among sites is likely stochastic. For Coryphaenoides brevibarbis, ranges of expected heterozygosity and allelic richness among sampling sites were similar to the range of values seen for $C$. rupestris $\left(H_{\mathrm{E}}: 0.74\right.$ to 0.79 , allelic richness: 11.34 to 12.19; White et al. 2010a).

There were no significant genetic differences between populations using $F_{\text {ST }}$ (Table 2) or exact tests (data not shown), and none of the AMOVAs revealed significant genetic differentiation between groups (Table 3).

\section{Demographic history of Coryphaenoides rupestris and C. brevibarbis}

DIYABC suggested that both species had undergone a period of population size decline, though the support for this is strongest for $C$. brevibarbis. For the first $C$. brevibarbis run including all samples, the posterior median of current $N_{\mathrm{e}}$ was estimated to be 8280 (95\% confidence limits, CL: 3100 and $21900)$, for a median mutation rate of $6.02 \times 10^{-4}\left(95 \%\right.$ CL: $1.71 \times 10^{-4}$ and $\left.9.63 \times 10^{-4}\right)$. The posterior distribution for past $N_{\mathrm{e}}$ was broad, but the $95 \% \mathrm{CL}$ did not overlap the distribution for the current $N_{\mathrm{e}}$ estimate (past $N_{\mathrm{e}}$ : 72 000; 95\% CL: 26800 and 97 700). The distribution for $t$, the time of population change, was also broad: 4910 generations (95\% CL: 807 to 39400 ). The posterior distribution for mean $P$ had a median of 0.30 (95\% CL: 0.299 and 0.300). Support for the scenario of a change in population size was higher than for a constant population (direct estimate: $99 \%$; logistic regression support $70 \%$ including the top 5000 simulations and $84.5 \%$ including the top 20000 simulations). All direct estimates were based on 500 simulations.

For the single Coryphaenoides brevibarbis population sample at NE1, the current $N_{\mathrm{e}}$ estimate was 6750 (95\% CL: 794 and 38400 ), for a median mutation rate of $3.66 \times 10^{-4}\left(95 \% \mathrm{CL}: 5.50 \times 10^{-5}\right.$ and $\left.5.91 \times 10^{-3}\right)$. The posterior distributions for past $N_{e}$ and $t$ were 
Table 2. Genetic differentiation between sampling sites. Pairwise $F_{\mathrm{ST}}$ values are shown below the diagonal, with p-values in parentheses. No values were significant when Bonferroni correction was applied (adjusted $\mathrm{p}=0.0024$ )

\begin{tabular}{|lcccccc|}
\hline Sampling site & SE1 & NE1 & NE2 & NE3 & NW1 & NW2 \\
\hline NE1 & $0.003(0.208)$ & - & & & & \\
NE2 & $0.001(0.264)$ & $0.002(0.237)$ & - & & & \\
NE3 & $-0.002(0.922)$ & $0.001(0.469)$ & $-0.001(0.840)$ & - & - & - \\
NW1 & $-0.001(0.683)$ & $0.001(0.319)$ & $-0.001(0.647)$ & $0.001(0.276)$ & & \\
NW2 & $-0.003(0.938)$ & $0.000(0.566)$ & $-0.001(0.806)$ & $0.000(0.653)$ & $0.001(0.103)$ & $0.000(0.505)$ \\
SE2 & $0.003(0.094)$ & $0.000(0.587)$ & $-0.002(0.835)$ & $0.001(0.359)$ & $0.005(0.017)$ & - \\
\hline
\end{tabular}

broad, with past $N_{\mathrm{e}}$ having a median of $63400(95 \%$ CL: 14700 and 96700 ), and $t$ having a median of 10800 generations (95\% CL: 1390 and 65900$)$ ). The posterior distribution for mean $P$ had a median of 0.298 (95\% CL: 0.245 and 0.300 ). The support for the changing population size scenario was $84 \%$ for the direct estimate and $78 \%$ for the logistic regression estimate for the top 5000 simulations.

For the first Coryphaenoides rupestris estimate based on the sample from SE1, the posterior median of current $N_{\mathrm{e}}$ was estimated to be 6280 (95\% CL: 503 and $73100)$, for a median mutation rate of $1.57 \times 10^{-3}(95 \%$ CL: $8.20 \times 10^{-5}$ and $9.31 \times 10^{-3}$ ). The posterior distributions for past $N_{\mathrm{e}}$ and $t$ were broad, with past $N_{\mathrm{e}}$ having a median of 20700 (95\% CL: 1470 and 83200 ), and $t$ having a median of 54700 generations (95\% CL: 7300 and 95900). The posterior distribution for mean $P$ had a median of 0.867 (95\% CL: 0.768 and 0.897). The support for the changing population size scenario was relatively weak (52\% for the direct estimate and $54 \%$ for the logistic regression estimate for the top 5000 simulations). For C. rupestris at the second site (Faraday Seamounts), the posterior median of current $N_{\mathrm{e}}$ was estimated to be 4990 (95\% CL: 406 and 69600), for a median mutation rate of $1.88 \times 10^{-3}(95 \%$ CL: $1.00 \times$ $10^{-4}$ and $9.46 \times 10^{-3}$ ). The posterior distributions for past $N_{\mathrm{e}}$ and $t$ were broad, with past $N_{\mathrm{e}}$ having a median of 25200 (95\% CL: 1990 and 86 400), and $t$ having a median of 56100 generations (95\% CL: 7380 and 96 200). The posterior distribution for mean $P$ had a median of 0.892 (95\% CL: 0.847 and 0.900). The support for the changing population size scenario was stronger for this sample (55\% for the direct estimate and $64 \%$ for the top 5000 simulations).
Table 3. Results of AMOVAs. Groupings are (A) north versus south of the SubPolar Front (SPF), (B) west and east of the Mid-Atlantic Ridge (MAR), (C) NW, NE, SW, SE and (D) broad geographic clusters given in Table 1

\begin{tabular}{lccc|}
\hline Source of variation & df & $\begin{array}{c}\text { Sum of } \\
\text { squares }\end{array}$ & $\begin{array}{c}\text { Percentage } \\
\text { of variation }\end{array}$ \\
\hline (A) North vs. south of the SPF & & & \\
Among groups & 1 & 4.503 & -0.12 \\
Among populations within groups & 5 & 29.271 & 0.04 \\
Among individuals within populations & 753 & 4230.406 & 100.08 \\
& & & \\
(B) West and east of the MAR & 1 & 4.889 & -0.05 \\
Among groups & 5 & 28.886 & 0.03 \\
Among populations within groups & 753 & 4230.406 & 100.02 \\
Among individuals within populations & & & \\
& & & \\
(C) NW, NE, SW, SE & 2 & 9.389 & -0.11 \\
Among groups & 4 & 24.386 & 0.09 \\
Among populations within groups & 753 & 4230.406 & 100.03 \\
Among individuals within populations & & & \\
& & & \\
(D) Broad geographic clusters & 3 & 15.981 & -0.06 \\
Among groups & 3 & 17.793 & 0.05 \\
Among populations within groups & 753 & 4230.406 & 100.01 \\
Among individuals within populations & & & \\
\hline
\end{tabular}

\section{DISCUSSION}

Little is known about most of the species in the genus Coryphaenoides, but some are found primarily in water $>2 \mathrm{~km}$ deep (including C. brevibarbis), which may mean that either the physical barrier of the MAR rising about $3.2 \mathrm{~km}$ above the surface of the ocean floor on average or its impact on deep sea currents could act as a barrier to gene flow. Our study found no genetic differentiation across the MAR for $C$. brevibarbis, and while some differentiation across the SPF (though at a low level) was seen for C. rupestris (White et al. 2010a), no population structure was found for C. brevibarbis.

White et al. (2010a) suggested that larval distribution on distinct current systems either side of the SPF may have explained the detected genetic 
differentiation of Coryphaenoides rupestris. Surface currents in the North Atlantic create a clockwise gyre south of the SPF and a tendency for north-eastward flow north of the SPF. Deep water currents show a distinct pattern. For example, the North Atlantic Deep Water (NADW) flow runs at a depth of about 2 to $4 \mathrm{~km}$ north to south and into the South Atlantic. As described in the introduction, C. brevibarbis represents a relatively deep water species, reaching depths of up to $4700 \mathrm{~m}$ (range $=1500$ to $4700 \mathrm{~m}$ ), while C. rupestris is found mostly in shallower water (180 to $2600 \mathrm{~m}$ ). Although the depth ranges of the 2 species overlap, if current systems dominated by flow at the surface are affecting gene flow in $C$. rupestris, it may be that $C$. brevibarbis inhabits waters too deep to be similarly affected. It is known that the eggs of C. rupestris are buoyant (Bergstad 1990), which could bring them into the surface current system, but little is known about the reproductive biology of $C$. brevibarbis.

As described above, a subset of species in the genus Coryphaenoides can live in waters deeper than $4 \mathrm{~km}$ (abyssal species). Morita (1999) compared 2 such species (C. armatus and C. yaquinae) with 5 shallower water species (with depth ranges that are unlikely to overlap with $C$. armatus and $C$. yaquinae) from the same genus (C. pectoralis, C. acrolepis, C. longifilis, C. cinereus and $C$. nasutus) at the $12 \mathrm{~S}$ and COI mtDNA genes and showed that the 2 abyssal species grouped together. This was consistent with a study by Wilson et al. (1991) showing that C. armatus and another abyssal species, C. leptolepis, grouped together in a tree based on peptide mapping at the LDH-A $\mathrm{A}_{4}$ gene. We extend and further support this inference based on the comparison of 6 abyssal (out of 8 abyssal species in the genus) and 4 shallower water species at the COI locus, confirming the support for 2 lineages based on habitat depth. These analyses are preliminary (a full understanding must wait for a more inclusive set of Coryphaenoides species based on multiple genetic markers) and the potential relevance of overlapping depth ranges for some species is not clear, but together the current data suggest that our 2 focal species may each belong to a distinct lineage defined by the deepest range of its habitat. This is important for the present study because it suggests that aspects of habitat type with respect to depth are defining the radiations of these species, which would strengthen their utility in a comparative analysis (yet more work will be necessary to determine whether depth is the primary factor, e.g. although we found no correlation with location, relatively few species were included in the phylogeny). Relevant to this, Morita (2008) compared 2 deep water and 2 shallower water Coryphaenoides species and showed that myosin heavy chain proteins differ in ways that may be associated with adaptation to pres- sure. Some species show intraspecific neutral genetic differentiation among populations at different depths (e.g. Knutsen et al. 2009, White et al. 2010a), and for $C$. rupestris this was associated with local selection (White et al. 2010a), though the relevant functional locus could not be identified.

The precise impact of historical environmental change on ocean currents is unknown; however, it is likely that currents at depth were affected differently than those at the surface. For example, sediment core data from the Bermuda rise showed that the rapid climatic transitions at the start and end of the last interglacial period are associated with abrupt changes in deep water flow, representing changes that occurred over periods of just a few hundred years (Adkins et al. 1997). Related factors may have differentially affected species occupying habitat at different depths.

Both species showed relatively high estimated historical effective population sizes (median estimates of from 63400 to 72000 for Coryphaenoides brevibarbis and from 20700 to 22500 for C. rupestris), though the confidence limits were broad, especially for C. rupestris. These values are consistent with current population size estimates for some other North Atlantic species, including Antimora rostrata (30000; White et al. 2010a) and Mycteroperca microlepis (16 500; Cushman et al. 2009). For each of the study species, however, current $N_{\mathrm{e}}$ estimates were lower (median estimates of from 6750 to 8280 for C. brevibarbis and from 4990 to 6280 for C. rupestris), more comparable to an estimated 2190 for current $N_{\mathrm{e}}$ in the orange roughy Hoplostethys atlanticus (White et al. 2009b). In each case, the scenario for a population decline had higher posterior support than a model for constant population size (and repeat analyses for each species gave similar results), though the support for this was stronger for C. brevibarbis, consistent with the indications of a more severe decline. Only C. brevibarbis showed non-overlapping $N_{\mathrm{e}}$ estimates for historical compared to current distributions, and this fact reinforces the likelihood that this species experienced a decline. The associated timeframes were since the last interglacial, though the median estimates were more recent for C. brevibarbis (4910 to 10800 generations) than for C. rupestris (54 700 to 56100 generations). Taken together the data suggest a greater decline over a shorter time span for C. brevibarbis (and stronger support for the signal of decline) than for $C$. rupestris, which may indicate a greater impact on the species adapted to habitat at greater depth. As a theoretical possibility, it may be consistent with a strong impact of climatic variation (e.g. in association with glacial epochs) on deep-water flow (e.g. Adkins et al. 1997), though the specific mechanism of how change in the current systems may lead to population decline is not clear. It is also not clear 
what impact the potential for $C$. brevibarbis to live at depths overlapping those inhabited by $C$. rupestris may have. Both species are also taken in large numbers in deep water trawl fisheries (though not well estimated for C. brevibarbis, and possibly less due to its distribution in deeper water), and therefore a recent decline related to these fisheries may have also influenced our present day $N_{\mathrm{e}}$ estimates (though our estimates of the time for the start of a decline in each species are too old to reflect a fisheries impact).

The conservation and management relevance of our data depends in part on the relationship between the effective and census population size. However, this relationship is poorly understood for marine fish species. Portnoy et al. (2008) reviewed estimated $N_{\mathrm{e}} / N$ ratios for marine fish and report a range from 0.00001 to 0.5 . The most extreme at the low end was based on an estimated census size of $\sim 100000000$ plaice Pleuronectes platessa compared to an $N_{\mathrm{e}}$ of from 2000 to 20000 (Hoarau et al. 2005). At the other extreme was an estimated $N_{\mathrm{e}} / N$ ratio of about 0.5 for the sandbar shark Carcharhinus plumbeus (Portnoy et al. 2008). Various factors may contribute to the large variation in $N_{\mathrm{e}} / N$ ratio values, including variation in family size, unequal contributions from males and females, and non-random mating (Hedgecock 1994, Hedrick 2005). In marine fish species, it has been suggested that high variance in reproductive success among individuals ('sweepstakes breeders') in particular could greatly depress the value of $N_{\mathrm{e}}$ in relation to $N$ (e.g. Hedrick 2005, Hoarau et al. 2005).

For our study species, each shows some indication of positive $F_{\text {IS }}$ values, which could be consistent with a sweepstake breeding strategy, but the data on census numbers are insufficient to draw any strong conclusions about $N_{\mathrm{e}} / N$ ratios. It is known that from 7000 to $42000 \mathrm{t}$ of Coryphaenoides rupestris were taken each year in trawl fisheries in the North Atlantic between 1970 and 2008 (FAO 2010), and, although similar data are not available for $C$. brevibarbis, the bycatch is thought to be substantial. Therefore, given the relatively small $N_{\mathrm{e}}$ estimates, the $N_{\mathrm{e}} / N$ ratios are likely to be small. This is problematic for management since conservation should be based on $N_{\mathrm{e}}$, while the large census numbers suggest a healthy stock.

Our data suggest that the deeper water species showed less evidence of population structure, and potentially a more extreme, faster population decline since sometime during the last glaciation. Given the investment required to acquire these data for a given species, a clearer indication of the potential role of habitat depth in determining the different patterns will likely have to wait for a meta-analysis, after data are available for a broader range of species. However, there is precedent for abyssal species showing less population genetic structure than conspecifics or related species at shallower depths. Of course, highly mobile species will in most cases require inter-specific comparisons for evidence of structure associated with genetic drift, as individuals can migrate in the water column and habitat use by depth can vary over small geographic ranges for these species (e.g. C. rupestris; White et al. 2010a). Comparisons among populations of the deep sea bivalve Deminucula atacellana showed a strong association between population differentiation and depth, with comparisons at the greatest depths (down to $3000 \mathrm{~m}$ ) showing the lowest values of $\phi_{\mathrm{ST}}$ (based on comparisons of 16S mtDNA sequences; Zardus et al. 2006). In another study, 4 bivalve species were compared, and the species found at the greatest depth (down to $4800 \mathrm{~m}$ ) showed the shallowest radiations of 16S mtDNA sequence haplotypes and the least differentiation among populations (Etter et al. 2005). A similar effect was seen for the cosmopolitan deep sea amphipod Eurythenes gryllus (France \& Kocher 1996). There have been various suggestions about how dispersal potential, reduced habitat complexity, or depthrelated variation in mutation rates may lead abyssal species to show reduced population structure (e.g. see the discussion in Etter et al. 2005); however, little is presently known about these species or the relevant systems. The specious genus Coryphaenoides, which includes 8 abyssal species, should be a useful system in which to explore these questions further.

Acknowledgements. This project is part of ECOMAR, a NERCfunded element of MARECO, which in turn is a field project of the Census of Marine Life. We thank Ingvar Byrkjedal and the Bergen Museum for the provision of samples, and Jeff Mashburn, Rob Simpson, Nikki King, Ben Boorman, Halvor Knutsen and the crew of the ECOMAR cruises for help with the acquisition of fish samples. We thank Odd Aksel Bergstad and the MARECO project for additional support funding.

\section{LITERATURE CITED}

Adkins JF, Boyle EA, Keigwin L, Cortijo E (1997) Variability of the North Atlantic thermohaline circulation during the last interglacial period. Nature 390:154-156

Amos W, Hoffman JI, Frodsham A, Zhang L, Best S, Hill AVS (2006) Automated binning of microsatellite alleles: problems and solutions. Mol Ecol Notes 7:10-14

Atkinson DB (1995) The biology and fishery of roundnose grenadier (C. rupestris Gunnerus, 1765) in the north-west Atlantic. In: Hopper AG (ed) Deep-water fisheries of the North Atlantic Oceanic Slope. Kluwer Academic Publishers, Amsterdam, p 51-112

Balding DJ, Nichols RA (1995) A method for quantifying differentiation between populations at multi-allelic loci and its implications for investigating identity and paternity. Genetica 96:3-12

$>$ Bergstad OA (1990) Distribution, population structure, growth and reproduction of the roundnose grenadier 
Coryphaenoides rupestris (Pisces: Macrouridae) in the deep waters of the Skagerrak. Mar Biol 107:25-39

Bergstad OA, Gordon JDM (1994) Deep-water ichthyoplankton of the Skagerrak with special reference to Coryphaenoides rupestris Gunnerus, 1765 (Pisces, Macrouridae) and Argentina silus (Ascanius, 1775) (Pisces, Argentinidae). Sarsia 79:33-43

Bergstad OA, Hoines AS, Orlov AM, Iwamoto T, Galbraith J, Byrkjedal I, Uiblein F (2008a) Species composition and abundance patterns of grenadiers on the Mid-Atlantic Ridge between Iceland and the Azores. In: Orlov AM, Iwamoto T (eds) Grenadiers of the world oceans: biology, stock assessment, and fisheries. Am Fish Soc Symp 63: 65-80

Bergstad OA, Menezes G, Høines AS (2008b) Demersal fish on a mid-ocean ridge: distribution patterns and structuring factors. Deep Sea Res II 55:185-202

Blank J, Stauss M, Tomiuk J, Fietz J, Segelbacher G (2007) Habitat type does not affect population genetic structure in sympatric great tits (Parus major) and blue tits $(P$. caeruleus). J Negative Results - Ecol Evol Biol 4:1-14

Coad BW, Reist JD 2004 Annotated list of the arctic marine fishes of Canada. Can Manuscr Rep Fish Aquat Sci 2674

Cornuet JM, Santos F, Beaumont MA, Robert CP and others (2008) Inferring population history with DIY ABC: a userfriendly approach to approximate Bayesian computation. Bioinformatics 24:2713-2719

Cushman EL, Jue NK, Strand AE, Sotka EE (2009) Evaluating the demographic significance of genetic homogeneity using a coalescent-based simulation: a case study with gag (Mycteroperca microlepis). Can J Fish Aquat Sci 66: 1821-1830

Devine JA, Baker KD, Haedrich RL (2006) Deep-sea fishes qualify as endangered. Nature 439:29

Etter RJ, Rex MA, Chase MR, Quattro JM (2005) Population differentiation decreases with depth in deep-sea bivalves. Evolution 59:1479-1491

Excoffier L, Lischer HEL (in press) Arlequin suite Ver. 3.5: a new series of programs to perform population genetics analyses under Linux and Windows. Mol Ecol Resour

FAO (Food and Agriculture Organization) (2010) Species fact sheet for Coryphaenoides rupestris. Available at: www. fao.org/fishery/species/3035/en

Foll M, Gaggiotti OE (2008) Estimating selection with different markers and varying demographic scenarios: a Bayesian perspective. Genetics 180:977-993

France SC, Kocher TD (1996) Geographic and bathymetric patterns of mitochondrial 16S rDNA sequence divergence among deep-sea amphipods, Eurythenes gryllus. Mar Biol 126:633-643

Gordon JDM, Bergstad OA (1992) Species composition of demersal fish in the Rockall Trough, north-eastern Atlantic, as determined by different trawls. J Mar Biol Assoc UK 72:213-230

Gordon JDM, Duncan JAR (1987) Deep-sea bottom-living fishes at two repeat stations at 2200 and $2900 \mathrm{~m}$ in the Rockall Trough, northeastern Atlantic Ocean. Mar Biol 96: 309-325

Hedgecock D (1994) Does variance in reproductive success limit effective population sizes of marine organisms? In: Beaumont M (ed) Genetics and evolution of aquatic organisms. Chapman \& Hall, London, p 122-134

Hedrick P (2005) Large variance in reproductive success and the $\mathrm{Ne} / \mathrm{N}$ ratio. Evolution 59:1596-1599

Hoarau G, Boon E, Jongma DN, Ferber, S and others (2005) Low effective population size and evidence for inbreeding in an overexploited flatfish, plaice (Pleuronectes platessa
L.). Proc Biol Sci 272:497-503

Hoelzel AR (1998) Molecular genetic analysis of populations: a practical approach. Oxford University Press, Oxford

> Huelsenbeck JP, Ronquist F (2001) MRBAYES: Bayesian inference of phylogeny. Bioinformatics 17:754-755

ICES (International Council for the Exploitation of the Sea) (2002) Report of the ICES working group on the biology and assessment of deep-sea fisheries resources. ICES CM 2002/ACFM:16

Knutsen H, Le Goff-Vitry M, Fiani D, Hoelzel AR (2008) Isolation and characterization of microsatellite loci in the deep-sea marine fish, the roundnose grenadier (Coryphaenoides rupestris). Mol Ecol Resour 8:993-995

Knutsen H, Jorde PE, Sannæs H, Hoelzel AR and others (2009) Bathymetric barriers promoting genetic structure in the deepwater demersal fish tusk Brosme brosme. Mol Ecol 18:3151-3162

Koslow JA, Boehlert GW, Gordon JDM, Haedrich RL, Lorance P, Parin N (2000) Continental slope and deep-sea fisheries: implications for a fragile ecosystem. ICES J Mar Sci 57: 548-557

Marten A, Brändle M, Brandl R (2006) Habitat type predicts population differentiation in freshwater invertebrates. Mol Ecol 15:2643-2651

> Morita T (1999) Molecular phylogenetic relationships of the deep-sea fish genus Coryphaenoides (Gadiformes: Macrouridae) based on mitochondrial DNA. Mol Phylogenet Evol 13:447-454

> Morita T (2008) Comparative sequence analysis of myosin heavy chain proteins from congeneric shallow- and deepliving rattail fish (genus Coryphaenoides). J Exp Biol 211: 1362-1367

Portnoy DS, McDowell JR, McCandless CT, Musick JA, Graves JE (2008) Effective size closely approximates the census size in the heavily exploited western Atlantic population of the sandbar shark, Carcharinus plumbeus. Conserv Genet 10:1697-1705

Posada D, Crandall KA (1998) MODELTEST: testing the model of DNA substitution. Bioinformatics 14:817-818

Raymond M, Rousset F (1995) GENEPOP (Version 1.2): population genetics software for exact tests and ecumenicism. J Hered 86:248-249

> Roa-Varon A, Orti G (2009) Phylogenetic relationships among families of Gadiformes (Teleostei, Paracanthopterygii) based on nuclear and mitochondrial data. Mol Phylogenet Evol 52:688-704

Ronquist F, Huelsenbeck JP (2003) MRBAYES 3: Bayesian phylogenetic inference under mixed models. Bioinformatics 19:1572-1574

> Ryman N, Palm S (2006) POWSIM: a computer program for assessing statistical power when testing for genetic differentiation. Mol Ecol Notes 6:600-602

Schneider M, Sannaes H, Jorder PE, Knutsen H (2009) Isolation and characterisation of 11 microsatellite loci in the abyssal carapine grenadier Coryphaenoides carapinus (Actinoperygii, Macrouridae) and cross amplification in two other deep-sea macrourid species. Conserv Genet 10: 1869-1871

Shikano T, Shimada Y, Herczeg G, Merila J (2010) History vs habitat type: explaining the genetic structure of European nine-spine stickleback (Pungitius pungitius) populations. Mol Ecol 19:1147-1161

Steinke D, Zemlak TS, Gavin H, Hebert PDN (2009) DNA barcoding fishes of the Canadian Pacific. Mar Biol 156: 2641-2647

- Van Oosterhout C, Hutchinson WF, Wills DPM, Shipley P (2004) MICRO-CHECKER: software for identifying and 
correcting genotyping errors in microsatellite data. Mol Ecol Notes 4:535-538

Weir BS, Cockerham CC (1984) Estimating F-statistics for the analysis of population structure. Evolution 38:1358-1370

$>$ White TA, Stamford J, Hoelzel AR (2008) Nine new microsatellite loci for the roundnose grenadier (Coryphaenoides rupestris) with four showing cross-amplification in the shortbeard grenadier ( $C$. brevibarbis). Conserv Genet 10:1421-1424

White TA, Stefanni S, Stamford J, Hoelzel AR (2009) Unexpected panmixia in a long-lived, deep-sea fish with welldefined spawning habitat and relatively low fecundity. Mol Ecol 18:2563-2573

White TA, Stamford J, Hoelzel AR (2010a) Local selection and

Editorial responsibility: Karen Miller,

Hobart, Australia population structure in a deep-sea fish, the roundnose grenadier (Coryphaenoides rupestris). Mol Ecol 19: 216-226

White TA, Fotherby HA, Hoelzel AR (2010b) Twelve new microsatellite loci for the shortbeard grenadier (Coryphaenoides brevibarbis). Conserv Genet Resour 2:189-191

Wilson RR, Siebenaller JF, Davis BJ (1991) Phylogenetic analysis of species of three subgenera of Coryphaenoides (Teleostei, Macrouridae) by peptide-mapping of homologs of LDH-A4. Biochem Syst Ecol 19:277-287

Zardus JD, Etter RJ, Chase MR, Rex MA, Boyle EE (2006) Bathymetric and geographic population structure in the pan-Atlantic deep-sea bivalve Deminucula atacellana (Schenck, 1939). Mol Ecol 15:639-651

Submitted: November 24, 2010; Accepted: May 11, 2011 Proofs received from author(s): July 8, 2011 